\title{
ÁREAS DEGRADADAS: TÉCNICAS DE REFLORESTAMENTO AMBIENTAL
}

\section{ARTIGO DE REVISÃO}

FERREIRA, Robson Soares ${ }^{1}$

SOUZA, Bruna Rodrigues de ${ }^{2}$

SIQUEIRA, Daiane Mesquita de ${ }^{3}$

SILVEIRA, Marcela Elida C. de S. ${ }^{4}$

GONÇALVES, Sérgio Luís ${ }^{5}$

SANTOS, Wilgo F. dos ${ }^{6}$

SANTIAGO, Yuri C. ${ }^{7}$

FERREIRA, Robson Soares. Et al. Áreas degradadas: Técnicas de

Reflorestamento Ambiental. Revista Científica Multidisciplinar Núcleo do Conhecimento. Ano 04, Ed. 06, Vol. 11, pp. 71-84. Junho de 2019. ISSN: 2448-0959

\footnotetext{
${ }^{1}$ MSc Engenharia Elétrica - UFU, Graduação em Engenharia Elétrica - UNIVALE.

2 Graduada em Engenharia Ambiental e Sanitária.

${ }^{3}$ Graduada em Engenharia Ambiental e Sanitária.

${ }^{4}$ Graduada em Engenharia Ambiental e Sanitária.

${ }^{5}$ Graduado em Engenharia Ambiental e Sanitária.

${ }^{6}$ Engenheiro Ambientalista e Sanitarista.

${ }^{7}$ Graduado em Engenharia Ambiental e Sanitária.
} 


\section{RESUMO}

O presente artigo tem por finalidade apresentar uma reflexão sobre os as técnicas de reflorestamento ambiental para minimizar os impactos causados pelo desmatamento em virtude do processo de urbanização crescente, bem como promover o crescimento sustentável para melhoria da qualidade de vida e manutenção para gerações futuras. As técnicas de reflorestamento ambiental vão desde o controle do pré-plantio, controle das plantas competidoras e preparo do solo para plantio, até a restauração de áreas degradadas.

Palavras-chave: reflorestamento ambiental, desmatamento, urbanização, áreas degradas.

\section{INTRODUÇÃO}

O presente artigo visa apresentar estratégias fundamentais para um possível reflorestamento em áreas já diagnosticadas como degradadas, podendo tais meios ser também utilizados para uso em áreas com possíveis prognósticos de destruição.

O solo é indiscutivelmente um dos mais importantes e valiosos recursos naturais que nos proporciona obtermos a sustentabilidade da qualidade de vida do ser humano. $O$ solo possui várias funções no ciclo dos nutrientes, no ciclo da água e, para a sustentabilidade dos sistemas naturais tais como os campos e florestas primárias, sendo um dos pontos mais relevantes na determinação da tipologia florestal.

As destruições ocasionadas pelo fato de tais áreas serem alvos de incessantes práticas danosas, de uso e de ocupação, na maioria das vezes advindas provindas de séculos passados, trazendo consigo uma grande bagagem de impactos negativos, que por fim se transfiguram em uma destruição fracionada ou até mesmo total em uma área.

Segundo Kageyama, Reis e Carpanezzi (1992) áreas degradadas são aquelas que após a ocorrência de algum tipo de distúrbio têm seus meios de regeneração 
eliminados ou prejudicados. Estes distúrbios podem ser provenientes da mineração, do uso intensivo do solo por agropecuários, queimadas consecutivas ou desmatamento do solo. A recuperação destas áreas tem como principal objetivo proporcionar ao meio ambiente condição para que ele se recupere da degradação sofrida.

Fazendo uso das vantagens, bem como das condições oferecidas pelo país, pode-se trazer à tona a motivação dessas práticas de reflorestamento, que consigo trazem benefícios imensuráveis e melhoras significativas de vida da população, da qualidade do próprio ambiente, dentre outros.

Se for comprovado que práticas danosas tem se tornado cada vez mais frequentes, tomando dimensões cada vez maiores, deve-se aplicar técnicas de reflorestamento de forma a alcançar resultados mais eficazes, trazendo à tona a questão da preocupação com a melhora da qualidade e preservação ambiental.

Segundo Marcone (2015, p. 513):

A Constituição da República Federativa do Brasil, no capítulo VI, estabelece no Artigo 225, parágrafo $2^{\circ}$, que "aquele que explorar recursos minerais fica obrigado a recuperar o meio ambiente degradado, de acordo com solução técnica exigida pelo órgão público competente, na forma da lei".

Marcone (2015, p. 513) diz que:

O Plano de Recuperação de Áreas Degradadas - PRAD considera as atividades referentes à recuperação, levando em conta o papel fundamental que a cobertura vegetal ocupa no contexto de reabilitação ambiental e ecológica das áreas interferidas, destacando-se: atividades a serem desenvolvidas anteriormente e conjuntamente à supressão vegetal, criando condições para maximizar as práticas de vegetação; os planos de recuperação e sua execução, descrevendo as práticas de 
recuperação e estabilização da área; o monitoramento das áreas recuperadas, fechamento e descomissionamento de estruturas com a indicação de seu uso futuro.

\section{OBJETIVO}

O presente artigo visa analisar e descrever as formas de recuperação e preservação de florestas em áreas diagnosticadas como degradadas, bem como utilizá-las com a finalidade de preservar para as gerações futuras, promovendo a minimização dos impactos ambientais causados. Sendo a viabilidade técnica orientada pela lei 9985 (MMA, 2000).

\section{FUNDAMENTAÇÃO TEÓRICA}

\subsection{RESTAURAÇÃO FLORESTAL}

A restauração florestal, figura 1, representa um dos desafios para melhorar a qualidade do ambiente de propriedades e áreas protegidas: reservas legais, unidades de conservação e áreas de preservação permanente. A restauração florestal depende da aplicação de técnicas que visam restaurar o conjunto de dinâmica das florestas nativas da biodiversidade, ou seja, interação entre a fauna e flora, dos recursos hídricos através da proteção de nascentes de rios e corpos d'água, dos solos observando a função dos solos, e a minimização de processos erosivos. 
Figura 1: Recuperação de área degradada, em João Pessoa, PB.

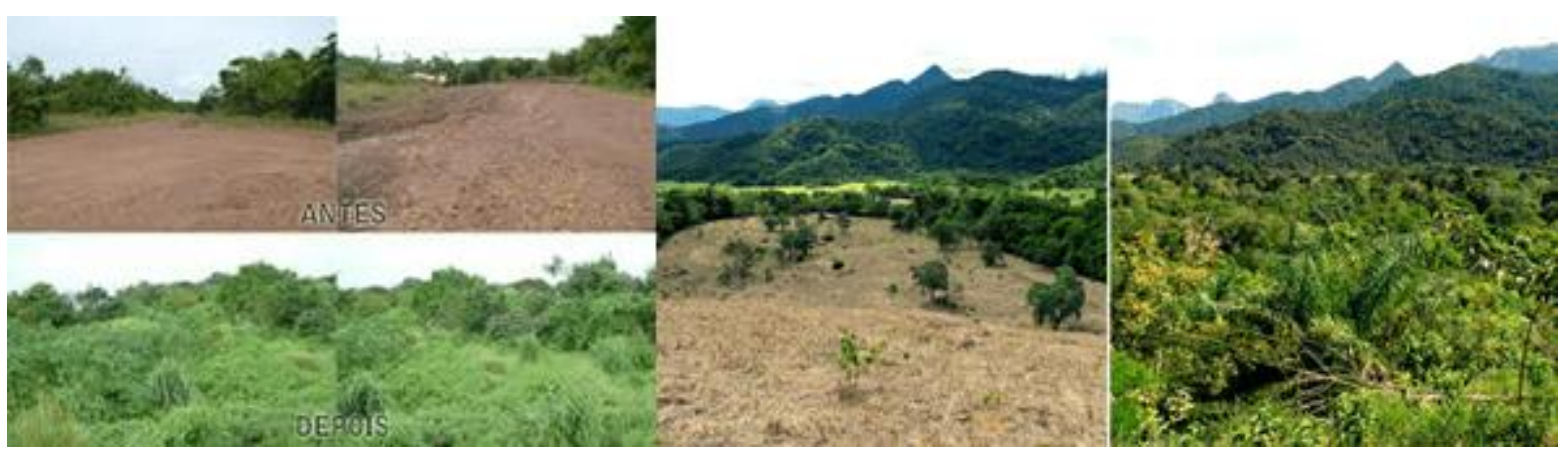

Fonte: Prefeitura de João Pessoa

A área a ser restaurada requer o emprego de técnicas adequadas a cada bioma, tais como: Mata Atlântica, Cerrado, Floresta Amazônica, etc. O objetivo nas unidades de conservação é incrementar as espécies vegetais e eliminar, progressivamente, as espécies exóticas e invasoras. Nas propriedades e reservas privadas, que não são classificadas como unidades de conservação privadas, é possível implementar projetos de manejo sustentável, reunindo conservação e aproveitamento de produtos florestais (agroflorestais), gerando benefícios tanto para os proprietários das áreas como para a comunidade local.

De acordo com Amador e Viana (1998, p. 106):

Um Sistema Agroflorestal (SAF) é um sistema de uso da terra conservacionista em que plantas de espécies agrícolas são combinadas com espécies arbóreas sobre a mesma unidade de manejo da terra. Apesar de, na maioria dos casos, ser um sistema visando à produção agrícola contínua, ele pode ser utilizado apenas como uma ferramenta para viabilizar economicamente os trabalhos de restauração de áreas degradadas. Conforme a combinação dos elementos componentes, os SAFs podem ser divididos em: silviagrícolas, silvipastoris, agrossilvipastoris e agroflorestais e, é um povoamento permanente, similar à floresta tropical nativa, com composição bastante diversificada e estratificada; fornece uma gama de estratégias para obtenção de um

Disponível em: https://www.nucleodoconhecimento.com.br/engenharia-ambiental/areas- 
desenvolvimento sustentável, conservando o solo e a água, reduzindo o uso de fertilizantes químicos e defensivos agrícolas, a correta adequação à pequena produção, bem como a conservação da biodiversidade e a recuperação de fragmentos florestais e matas ciliares.

\subsection{RECUPERAÇÃO DO SOLO}

A recuperação do solo, anterior a implantação de técnicas de reflorestamento se torna necessária devido ao fato das camadas superficiais do solo dispor de inúmeros nutrientes e matérias orgânicas, bem como propriedades físicas que favorecem a infiltração e armazenamento de água. Uma vez que essa camada é eliminada, resta somente o subsolo, e este não oferece condições propícias para uma progressão vegetal.

Uma das principais técnicas de recuperação do solo, reflorestamento, é a nucleação que é caracterizada por diversas técnicas implantadas, nunca em uma área total, mas em núcleos, deixando sempre espaços abertos para o eventual se expressar, ocupando em média $5 \%$ da área. As principais técnicas de nucleação são: transposição de galharia (abrigos artificiais), transposição de solo, transposição de mudas germinadas de chuva de sementes, poleiros artificiais, plantio de árvores em grupos de Anderson (REIS at. Al., 2006) apud (YARRANTON, 1974).

Segundo (WADT, 2003, p. 12):

São muitos e variados os processos que levam à degradação dos sistemas de produção do solo, em geral, as degradações ocorrem em duas fases: a primeira denominada degradação agrícola e, a segunda, degradação biológica. A degradação agrícola é o processo inicial no qual o sistema apresenta perda da produtividade econômica, com desequilíbrio pela ausência de ações no sentido de mantê-lo no ponto ideal de controle das ervas daninhas e de agentes bióticos adversos (fitopatógenos, pragas), resultando em menor produção da cultura principal. A degradação biológica consiste no processo final no qual há 
uma intensa diminuição da capacidade de produção de biomassa vegetal e é provocada, primariamente, pela degradação dos solos, ocasionada por diferentes processos que conduzem à perda de nutrientes e de matéria orgânica, e elevação da acidez ou da compactação. É nessa fase que os processos erosivos tornam-se evidentes. Provavelmente, para as condições de solo e clima de cada região, o processo mais importante seja a erosão hídrica, que consiste na perda da camada superficial do solo pelo escorrimento superficial da água.

A adoção de práticas de conservação do solo visa diminuir ou minimizar os efeitos destes dois principais processos erosivos (exposição e enxurrada), conciliando a exploração econômica com a preservação dos recursos naturais solo e água. Podendo-se destacar como benefícios, tal método tende a aumentar a aeração, a eficácia na absorção de água e a disponibilização de nutrientes, o que favorece em grande escala o processo de reflorestamento (WADT, 2003, p. 14),

\subsubsection{CONTROLE INICIAL: PRÉ-PLANTIO}

Segundo (Monsoy, 2018, p. 1):

O manejo de pré-plantio dispõe de inúmeros benefícios ao agricultor, assegurando a vantagem competitiva da cultura de interesse em relação às plantas daninhas, controlando as mesmas anteriormente ao plantio. Essa boa prática evita que problemas com a mato competição sejam causados e garante que a qualidade do plantio seja adequada, permitindo que a cultura tenha um desenvolvimento inicial rápido e vigoroso. Porém não dispensa que a área a ser manejada seja bem conhecida. Controle de plantas daninhas, anterior ao plantio evita problemas e traz garantias na qualidade do reflorestamento, pois permite um desenvolvimento inicial. 
O controle das plantas daninhas deve-se iniciar a pelo menos 30 dias antes do plantio ou até mesmo antes de qualquer ação de intervenção na área que será restaurada. Tal controle também se torna necessário em função do controle de ataque das formigas cortadeiras, figura 2 , as quais se sentirão ameaçadas com os procedimentos em campo, limitando suas atividades e alimentação, o que impossibilita obter um controle anterior ao início do processo de plantio.

Após esse controle inicial, de (05) cinco a (07) sete dias antes do plantio, é necessário um novo controle, que deve ocorrer novamente para verificação e início do plantio das mudas.

Figura 2: controle de formiga cortadeira

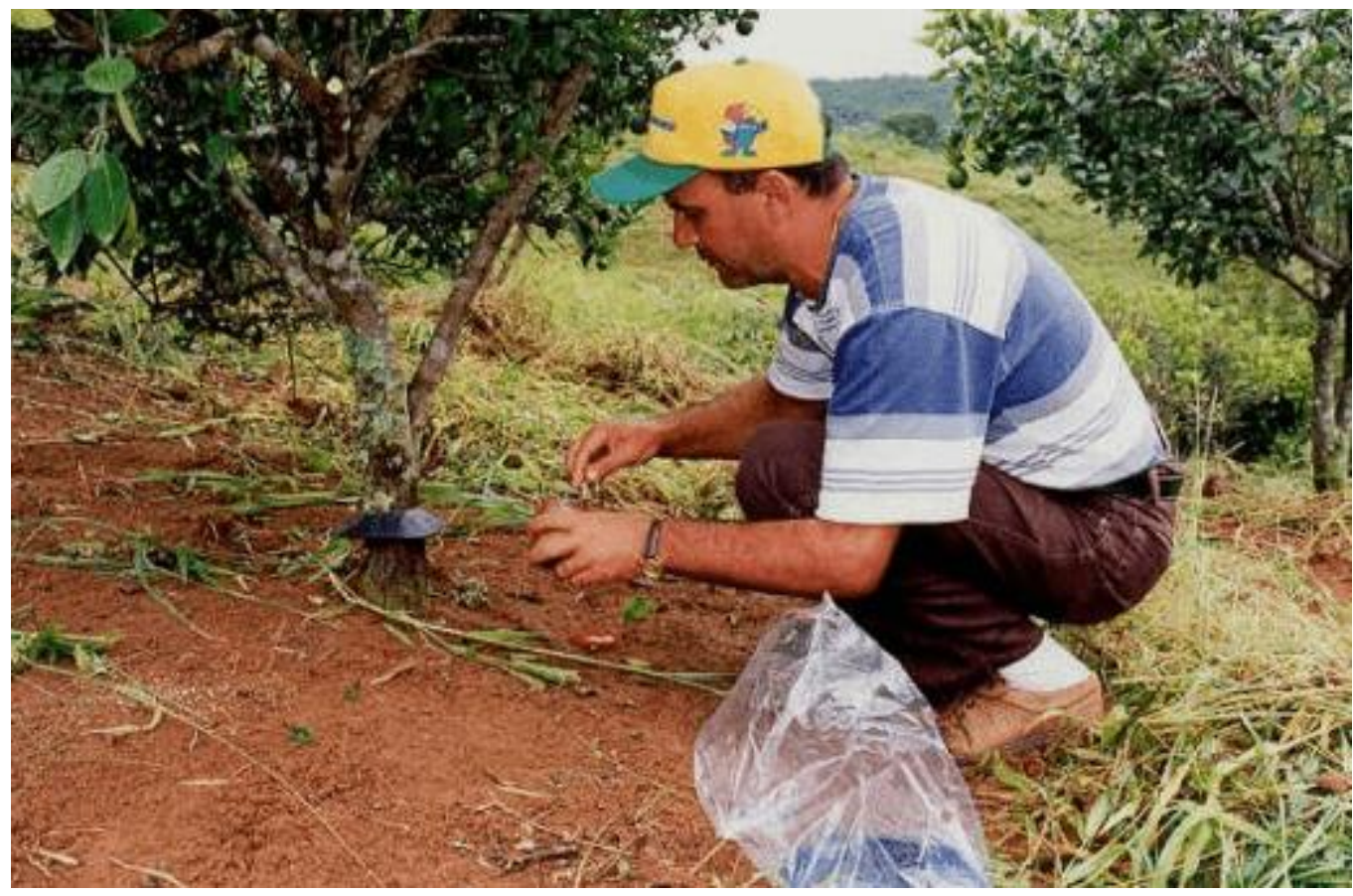

Fonte: www.cpt.com.br 


\subsubsection{CONTROLE DE PLANTAS COMPETIDORAS}

A maior parte das áreas a serem restauradas se encontra em estado de abandono, sendo assim elas podem ser ocupadas rapidamente por espécies competidoras e as espécies nativas da própria região.

Gandolfi e Sergius (2017), na maioria das vezes diversas espécies de árvores, palmeiras, etc. invadem e colonizam áreas abertas e abandonadas, edificando no local sólidas populações, as quais limitam uma reestruturação com espécies nativas locais. Existem inúmeros métodos operacionais para se executar o controle de tais espécies competidoras, que podem ser realizadas de forma química através de Herbicidas por exemplo, de forma mecânica utilizando maquinários e ferramentas, e também por meio de manejo criando condições que inibam que tais plantas se desenvolvam.

De início pode-se aplicar o controle através do uso de meios químicos ou físicos, figura 3 , devido que o manejo foi utilizado após ter ocorrido um controle inicial e, de certa forma deseja-se que não venha a ocorrer uma nova infestação dessas plantas competidoras. Dentre os métodos para controle, o que mais ocasionam controvérsias seria o método químico devido à utilização de herbicidas, que traz uma elevada ameaça de contágio ao solo, a água, bem como demais malefícios para o homem. 
Figura 3: Controle realizado por meio químico de área degradada.

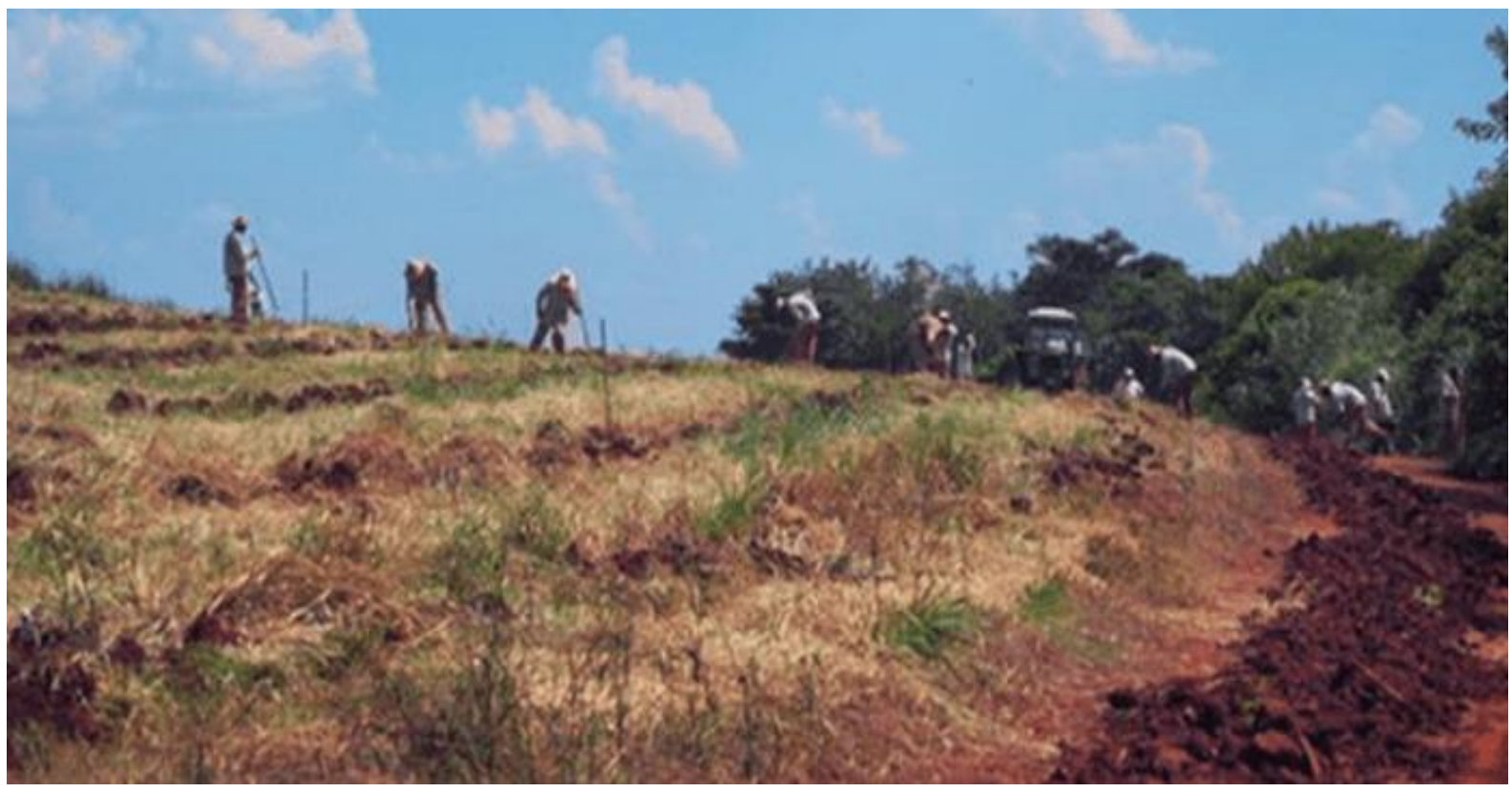

Fonte: (MARTINS, Sebastião Venâncio, 2013).

O controle inicial de algumas espécies pode ser realizado de forma mecânica, por meio do uso de roçadeira costal, figura 4, roçadeira tratorizada, capina com enxada e roçagem com foice, ou de forma química, por meio da aplicação de herbicidas dessecantes com costais e/ou com trator, utilizando-se barra ou mangueira de pulverização. 
Figura 4: Controle de plantas competidoras por meio de uso de maquinários e ferramentas.

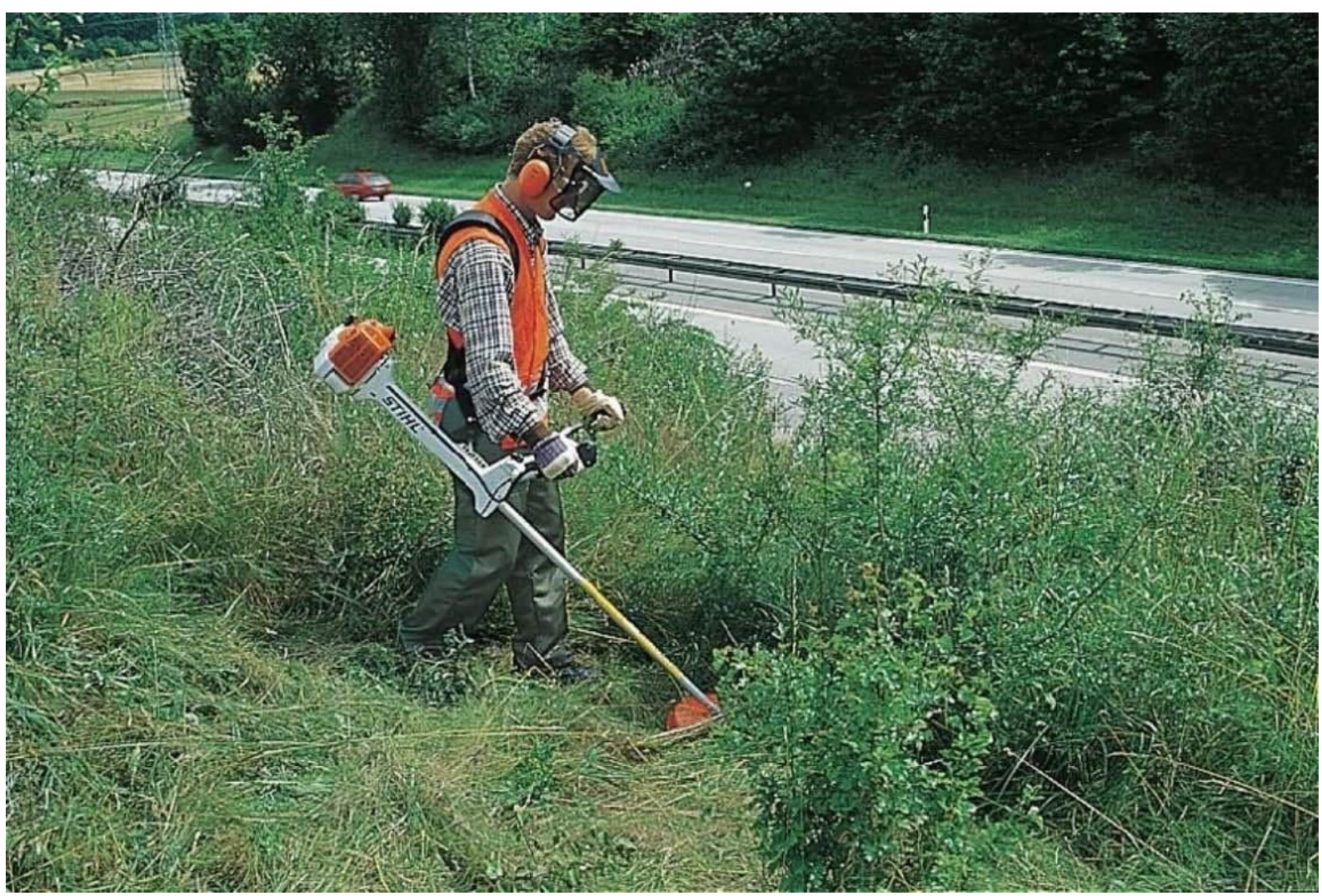

Fonte: chiareli.com

\subsubsection{PREPARO DO SOLO PARA PLANTIO}

Em primeiro lugar o preparo do solo tem por objetivo remover todo e qualquer contratempo físico, como camadas compactadas que possam limitar o crescimento das raízes nas mudas. Deve-se estar atento também para que essa ação não traga problemas como erosões e assoreamentos dos cursos d'água que podem afetar a vida das pessoas.

De acordo com Rosa (2015):

Existem várias técnicas para a recuperação de áreas degradadas, as que mais se destacam são: o plantio em linhas, plantio alternado e, os

Disponível em: https://www.nucleodoconhecimento.com.br/engenharia-ambiental/areasdegradadas 
sistemas agroflorestais. A técnica a ser empregada depende da seleção das espécies que pertencem ao bioma da área a ser recuperada. Não é aconselhável utilizar uma espécie endêmica da Mata Atlântica em um processo de recuperação de áreas de Cerrado.

As espécies escolhidas também devem ter fácil propagação e crescimento rápidos de forma a cobrir o solo e fornecer matéria orgânica ao ambiente. Ao escolher as sementes que atendem a estas exigências é necessário decidir como será realizado o plantio, que pode ser feito através de mudas ou de sementes plantadas. É fundamental que o plantio seja realizado no início da temporada de chuvas de forma a facilitar o seu crescimento.

Podendo ser realizado por um sistema principal em linha, realizado com o uso de subsolador florestal, figura 5 , com aproximadamente $50 \mathrm{~cm}$, a depender da profundidade da camada que se encontra compactada, que deve ser realizado seguindo as curvas de nível do terreno.

Figura 5: Preparo do solo com subsolador florestal.

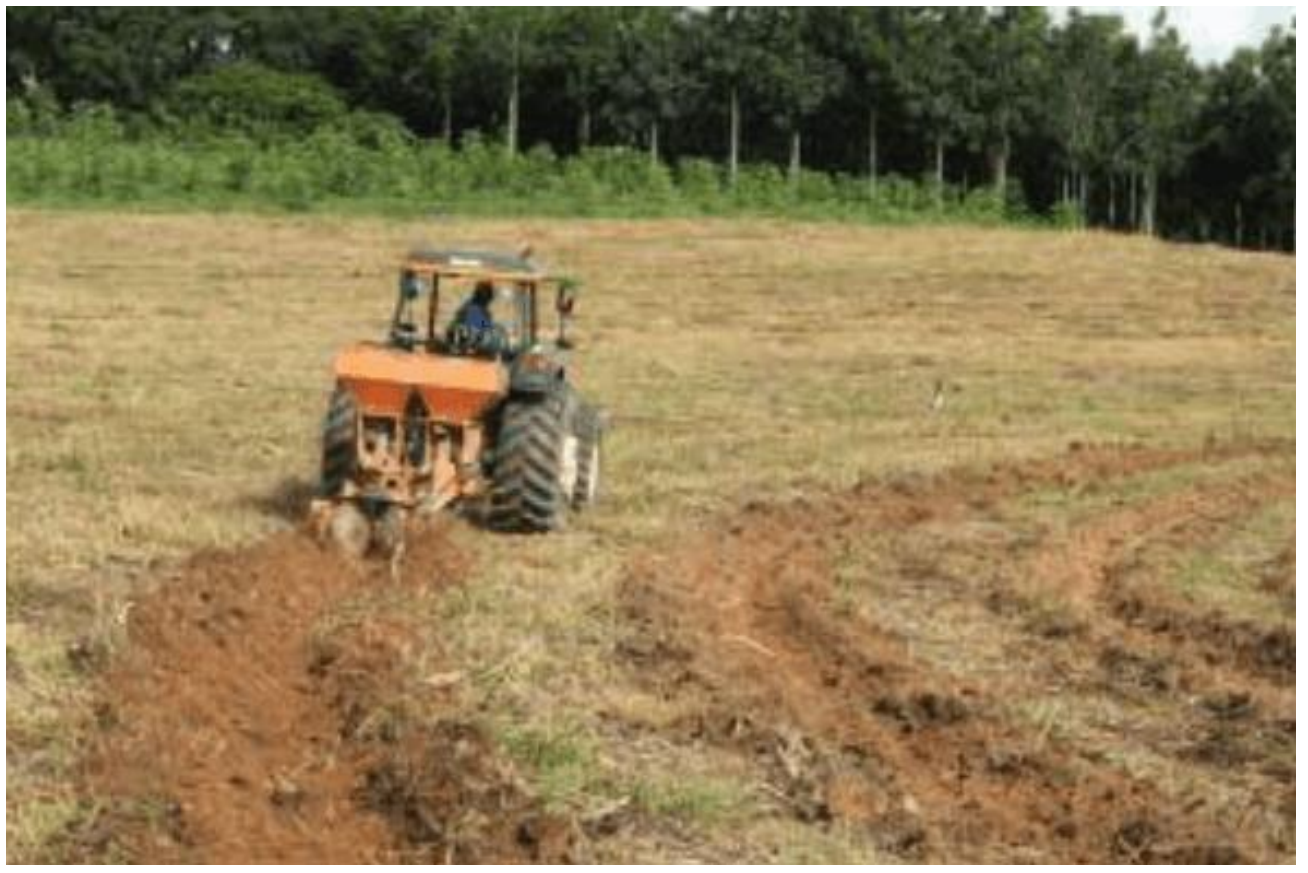

Fonte: belavistaflorestal.com.br

Disponível em: https://www.nucleodoconhecimento.com.br/engenharia-ambiental/areas- 
Essa técnica é utilizada em áreas com inclinações propícias para atividades de mecanização e sem elevação rochosa, ou solos rasos. A fim de se evitar que enxurradas decorrentes da chuva transformem os sulcos de plantio em erosão, a subsolagem deve ser feita seguindo curvas de nível. O subsolador é utilizado a fim de se preparar o solo para a semeadura direta, onde se faz necessário aguardar uma chuva que seja suficiente para que o solo das linhas de semeadura venha a se acomodar.

O plantio de mudas é uma forma eficaz de ampliar o processo de nucleação e, pode ser realizado de diversas maneiras, no que diz respeito à disposição das mudas em campo. A segunda forma de plantio seria o método em linha com espécie pioneira e não-pioneira, isto é, alternado, utilizando um espaçamento de $2 \times 3 \mathrm{~m}$ ou $2 \times 2 \mathrm{~m}$, conforme figura 6 .

Figura 6: Plantio em linhas alternadas de espécies pioneiras e não pioneiras.

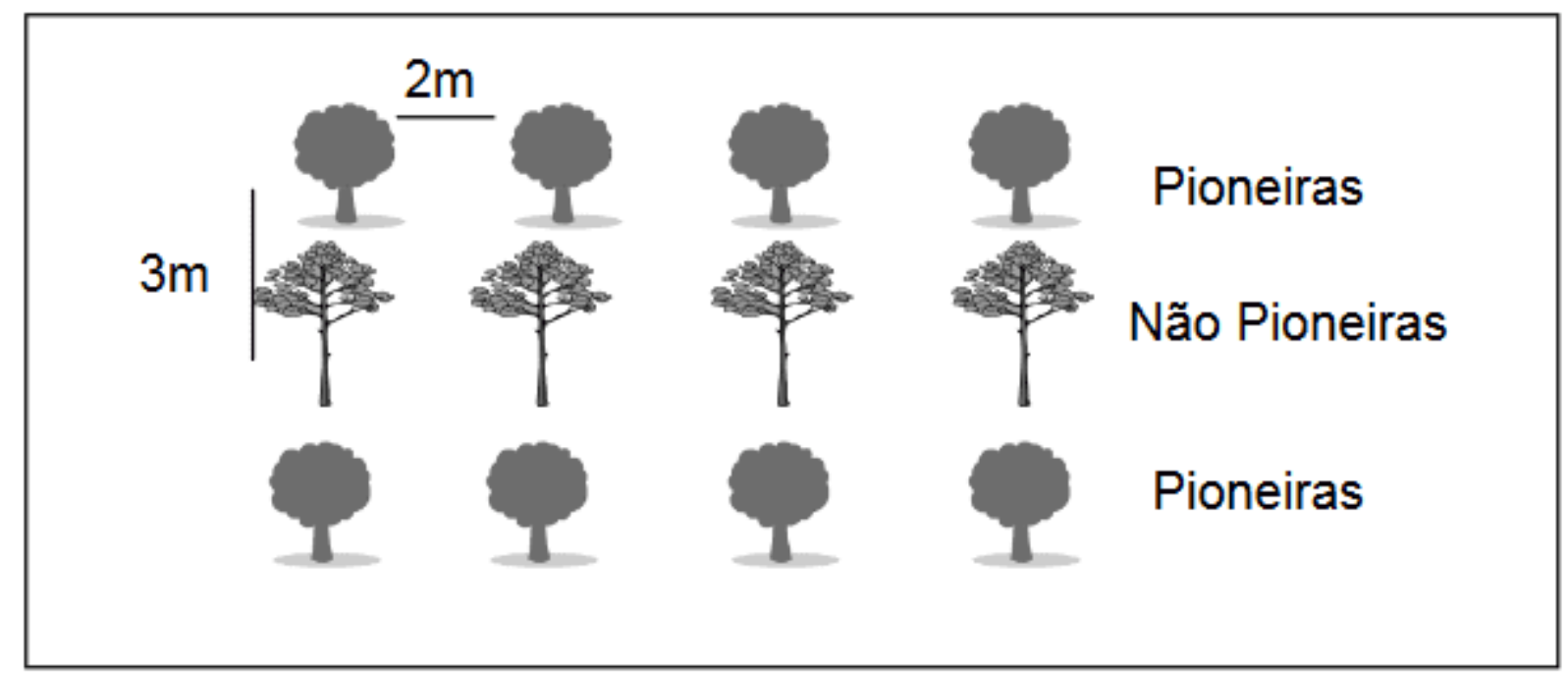

Fonte: SOARES, 2009.

Segundo (AMADOR, 1999, p. 3):

Sistema Agroflorestal é um novo nome para práticas antigas, desenvolvidas em grande parte por comunidades tradicionais em várias partes do mundo. Os SAFs consistem no cultivo simultâneo de espécies 
lenhosas e agrícolas em um mesmo espaço geográfico, no intuito de obter maior oferta de produtos, garantir a segurança alimentar e otimizar o espaço rural, permitindo uma produção sustentável.

A definição utilizada pelo ICRAF (Internacional Center for Research in Agroforestry) para Sistema agroflorestal - SAF é um nome coletivo para sistemas e tecnologias de uso da terra onde lenhosas e perenes são usadas deliberadamente na mesma unidade de manejo da terra com cultivares agrícolas e/ou animais em alguma forma de arranjo espacial e sequência temporal" (NAIR, 1993).

Os SAFs, figura 7, podem ser aplicados tanto como estratégia metodológica de recuperação, com o objetivo de reduzir os custos através da compensação a curto/médio prazo por produtos agrícolas/florestais, como para a constituição de agroecossistemas biodiversificados. Os sistemas agroflorestais têm papel de destaque na busca de alternativas para o desenvolvimento rural sustentável, principalmente por transformar as atividades de produção degradantes em regenerativas (VIANA et al, 1997).

As agroflorestas trazem uma proteção do solo contra erosão, a lixiviação e deslizamentos, assegurando o controle de fluxos de água através da melhoria da drenagem das chuvas e sequestro do carbono nas árvores. As práticas agroflorestais, ao respeitarem os processos naturais no desenvolvimento da vegetação, proporcionam um razoável nível de conservação da biodiversidade animal e vegetal (MICHON; DE FORESTA, 1999). 
Figura 7: Implantação de SAF.

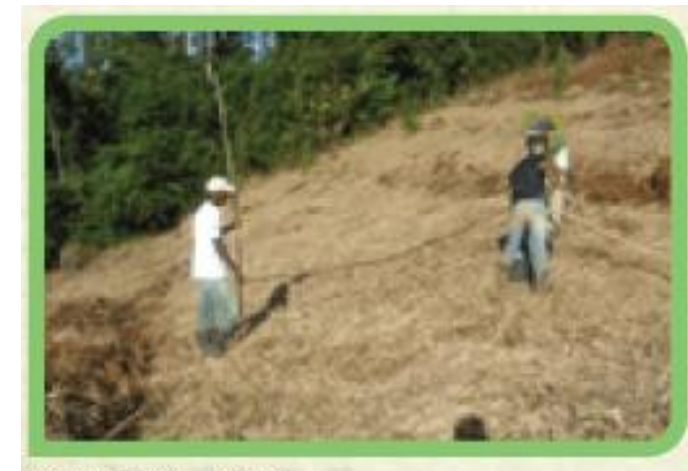

SAF antes - 2012

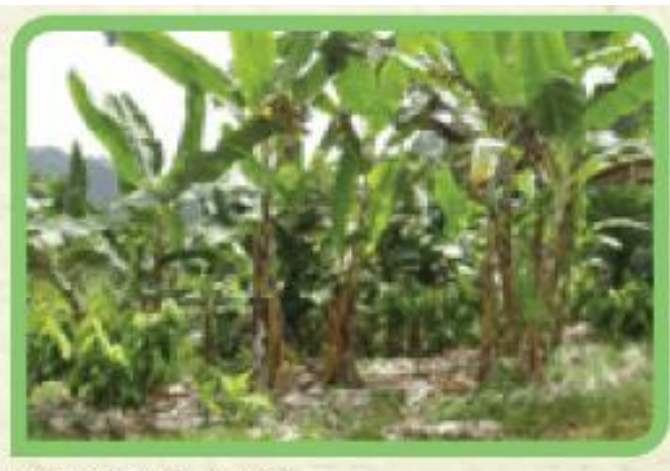

SAF depois - 2015

Fonte: oct.org.br

\subsection{RECUPERAÇÃO EM ÁREAS DEGRADA}

Em muitos projetos é citado que a restauração seria uma atividade praticamente impossível, já que as condições originais dificilmente são conhecidas e os rumos da sucessão secundária nem sempre podem ser previstos. Desta maneira, no Brasil predomina o uso dos termos recuperação e reabilitação ao invés de restauração (Engel \& Parrotta, 2008).

A implantação da recuperação de uma área degradada possui um grande objetivo que é minimizar as alterações ambientais que ocorreram durante todo o processo. A recuperação de uma área degradada também visa permitir que o espaço danificado consiga recuperar os recursos bióticos e abióticos necessários para manter-se em equilíbrio. O plano de recuperação deve prever a nova utilização da área de acordo com o plano de uso do solo predeterminado e, deve utilizar os princípios da sustentabilidade dos recursos naturais e a preservação dos ecossistemas como diretrizes para a sua recuperação.

Segundo (ANGELIS, 2000, p. 68) para um bom projeto de recuperação é necessário avaliar dados e informações, tais como: 
- Análise das regiões fitogeográficas em que estão localizadas as áreas a recuperar;

- Análise da vegetação ocorrente na região de localização das áreas a reabilitar;

- Seleção de espécies vegetais a serem introduzidas;

- Aquisição/produção de mudas;

- Análise físico-químicas do solo das áreas a reabilitar;

- Atividades de preparo e correção do solo para plantio;

- Seleção de espécies vegetais a serem introduzidas;

- Aquisição/produção de mudas;

- Atividades de plantio;

- Atividades de manutenção dos plantios;

- Avaliação e retroalimentação do sistema.

De acordo com (WADT, 2009, p. 13):

A erosão é o principal agente de remoção dos nutrientes depositados no solo logo após a queimada efetuada na floresta, conduzindo o solo à degradação biológica em poucos anos. As perdas de solo e da água através da erosão são especialmente intensas nas condições de alta pluviosidade que predomina em toda a Região Amazônica.

Segundo (WADT, 2009, p. 13):

Os processos erosivos são intensificados pela exposição direta do solo em contato com a água das chuvas e pela mineralização da biomassa vegetal logo após a utilização do fogo para promover a limpeza destas áreas, portanto, deve-se evitar a utilização do fogo no manejo de pastagens e áreas cultivadas de forma a diminuir a intensificação dos processos erosivos. A perda de nutrientes é bem mais crítica para o elemento fósforo, em virtude de sua importância para as plantas e por possuir baixas reservas nos solos. A maior parte do fósforo disponível para as plantas encontra-se retida na biomassa vegetal e, no processo 
de derrubada e queima, esse nutriente é incorporado às cinzas, atuando como o principal responsável pelos melhores índices de produtividade nos primeiros anos após a derrubada. Entretanto, a rápida diminuição das quantidades de fósforo assimilável no solo conduz inalteravelmente à perda de capacidade produtiva das áreas cultivadas.

O crescimento da população mundial trouxe a necessidade de vários incrementos da produção de minerais e da agropecuária, que vêm sendo implementados com a aplicação intensa de novas tecnologias e, tem alcançado novas fronteiras, contudo, tem-se observado alguns efeitos negativos, principalmente a degradação dos ecossistemas.

\section{METODOLOGIA}

Buscando analisar a temática proposta, este trabalho será pautado nas técnicas e equipamentos para se realizar os plantios, as fases pré-restauração, durante a restauração e pós-restauração, como são realizadas as manutenções, a necessidade ou não de replantio, as técnicas e produtos para adubação, também não menos importantes os custos para restauração.

Após o levantamento do material teórico através de pesquisa bibliográfica e descritiva em livros, revistas e artigos científicos, o estudo seguirá distribuído em quatro (04) fases distintas: A primeira o controle inicial do pré-plantio; A segunda o controle do plantio; A terceira os repasses de manutenção; A quarta o controle de plantas competidoras.

\section{CONCLUSÕES}

Esta pesquisa buscou analisar uma área degradada para promover sua recuperação, tendo como base os Métodos de Regeneração Natural e Reflorestamento, de forma a compensar os danos que foram causados, além de promover a reconstituição da paisagem local. 
Conclui-se que para recuperar uma área que foi impactada indevidamente é necessário que identifiquemos as principais questões relevantes, iniciando na descrição e no reconhecimento das condições ambientais da área afetada, além de um levantamento fitossociológico das espécies florestais, analisando as espécies florestais predominantes bem como as condições do solo.

$\mathrm{Na}$ identificação da biodiversidade, as características principais da área degradada fornecem uma lista preliminar das técnicas mais adequadas para sua recuperação, através da utilização da germinação de sementes e brotação de touças e raízes, obtêm-se a regeneração natural por processos naturais, que é responsável pelo processo de sucessão florestal.

A reutilização de áreas degradadas precisa vir acompanhada de estratégias de ação que promovem a recuperação rápida da sua capacidade produtiva, além do emprego de técnicas que promovam o seu desenvolvimento sustentável.

Portanto, a utilização de técnicas de preservação do solo e da recuperação de áreas degradadas previnem a degradação das áreas produtivas e invariavelmente a perda de áreas produtivas, enquadrando nas boas práticas de desenvolvimento sustentável e ambientalmente correto segundo o SAF, além de trazer benefícios tanto para o produtor como para toda a sociedade.

\section{REFERÊNCIAS}

AMADOR, D. B.; VIANA, V. M. Sistemas agroflorestais para recuperação de fragmentos florestais. Série Técnica. IPEF, Piracicaba, v. 12, n.32, p. 105-110, 1998.

ANGELIS NETO, G.; ANGELIS, B.L.D. A vegetação e sua importância no controle de áreas urbanas degradadas. In: SIMPÓSIO NACIONAL DE ÁREAS DEGRADADAS, 4. 2000, Blumenau - SC. Anais... Blumenau: FURB, 2000. p. 265.

BOTELHO, S. A. et al. Implantação de florestas de proteção. Lavras: Universidade Federal de Lavras/FAEPE, 2001. 81p. 
BRANCALION, P.H.S., Rodrigues, R.R., Gandolfi, S., Kageyama, P.Y., Nave, A.G., Gandara, F.B., Barbosa, L.M. \& Tabarelli, M.. Instrumentos legais podem contribuir para a restauração de florestas tropicais biodiversas. Revista Árvore, v. 34, p. 455470, 2010.

BUCK L.; LASSOIE, J. P.; E. FERNANDES, C. M. Agroforestry in Sustainable Agricultural Systems. Boca Raton, EUA: Lewis Publishers, 1999. p.381-406.

ENGEL, V.L. \& Parrotta, J.A. 2008. Definindo a restauração ecológica: tendências e perspectivas mundiais. In: P.Y. Kageyama, R.E. Oliveira, L.F.D. Moraes, V.L. Engel \& F.B. Gandara (orgs). Restauração ecológica de ecossistemas naturais. FEPAF, Botucatu, pp.1-26.

GANDOLFI, S. Uma Teoria sobre o Processo de Restauração Ecológica de Florestas Tropicais e Subtropicais: Proposta e Aplicação. Tese de Livre Docência, Escola Superior de Agricultura "Luiz de Queiroz", Piracicaba, SP. 105p., 2017.

GUIMARÃES, A.E.M.; VINICIUS, E.; SOUZA, ZACARIAS. Análise de recuperação de uma área degradada, na micro bacia do Ribeirão Taquaruçu - Palmas -TO. Faculdade Católica do Tocantins. 2009.

KAGeYAMA, P. Y., REIS, A., CARPANEZZI, A. A. Potencialidades e restrições da regeneração artificial na recuperação de áreas degradadas. In: SIMPÓSIO NACIONAL DE RECUPERAÇÃO DE ÁREAS DEGRADADAS, Curitiba, 1992. Anais. p. 1.

MARCONE, Karl Marx Nobre. Plano de Recuperação de Áreas Degradadas. Sudema. $\quad$ Paraíba: 2015.2 Disponível em: $<$ http://sudema.pb.gov.br/consultas/downloads/arquivos-eia-rima/casa-grande/eiacasa-grande/13-plano-de-recuperacao-de-areas-degradadas.pdf/view>>. Acesso em: 15 de maio 2018. 
MARTINS, Sebastião Venâncio. Recuperação de Áreas Degradadas. $3^{a}$ Ed. UFV: 2013.

MATIELLO, J.B.; DIAS, J. Renato; FRANCO, Lucas. Procafé: Sistemas de aplicação de herbicidas, para controle do mato, no pós-plantio do cafeeiro. SP: 2018. Disponível em: <<https://www.noticiasagricolas.com.br/noticias/cafe/207179-procafesistemas-de-aplicacao-de-herbicidas-para-controle-do-mato-no-pos-plantio-docafeeiro.html\#.XPgYa1YXddg>>. Acesso em 20 de maio 2018.

MICHON, G.; DE FORESTA, H. Agro-Forests: Incorporating a Forest Vision in Agroforestry.

NAIR, P. K. R. An Introduction to Agroforestry. The Netherlands, Kluwer Academic Publishers with ICRAF, 1993, $496 \mathrm{p}$.

REIS, Ademir; TRÊS, Deisy Regina; BECHARA, Fernando Campanhã. A Nucleação como Novo Paradigma na Restauração Ecológica: "Espaço para o Imprevisível". São Paulo: 2006.

ROSA, Mayara. 4 dicas para recuperar áreas com solo degradado. Ciclovivo. São Paulo: 2015. Disponível em: << http://dev.ciclovivo.com.br/planeta/meio-ambiente/4dicas-para-recuperar-areas-com-solo-degradado/>>. Acesso em 15 de maio 2018.

SOARES, Sílvia Maria Pereira. Técnicas de Restauração de Áreas Degradadas. Juiz de Fora: UFJF. 2009.

VIANA, V. M.; MATOS, J. C. de S.; AMADOR, D. B. Sistemas agroflorestais e o desenvolvimento rural sustentável no Brasil. XXVI CONGRESSO BRASILEIRO DE CIÊNCIA DO SOLO. Anais. EMBRAPA. Rio de Janeiro, 1997, $18 \mathrm{p}$

WADT, Paulo Guilherme Salvador. Práticas de Conservação do Solo e Recuperação de Áreas Degradadas. Ministério da Agricultura, Pecuária e Abastecimento. EMBRAPA. Acre: 2003. 
Lei 9985: Recuperação de Áreas Degradadas. Rio de Janeiro: 2000.

Art. 225 da Constituição Federal: Ordem social do Meio Ambiente.

$\mathrm{RJ}: 2017$.

Disponível

em:

$<$ https://www.senado.leg.br/atividade/const/con1988/con1988_06.06.2017/art_225_. asp>. Acesso em: 20 de maio 2018.

. Manejo Pré-Plantio. São Paulo: 2016. Disponível em: $<<$ www.monsoy.com.br/site/wp-content/uploads/2016/08/manejo_pre_plantio.pdf >>. Acesso em: 15 de maio 2018.

Enviado: Julho, 2018.

Aprovado: Junho, 2018. 